\title{
FRAGMENTO SACRO: Um exercício de aproximação entre a dialética negativa de Theodor Adorno e a hermenêutica teológica de Eberhard Jüngel*
}

\author{
SACRAL FRAGMENT \\ An exercise of approximation between the negative dialectic \\ of Theodor Adorno and the Theological Hermeneutics \\ of Eberhard Jüngel
}

Ronel Alberti da Rosa**

\section{RESUMO}

Nos Mandamentos, Deus proíbe aos homens tanto a feitura de imagens quanto a pronúncia em vão de Seu nome. Há, portanto, limites rígidos entre as esferas do sagrado e do humano. Este artigo examinará paralelos e divergências entre os pensamentos de dois autores que abordaram essa questão a partir de escolas de pensamento distintas: o filósofo neomarxista judeu Theodor Adorno e o teólogo luterano Eberhard Jüngel.

Palavras-chave: Dialética negativa. Indizibilidade de Deus. Não-idêntico. Nome de Deus.

* Todas as traduções foram feitas pelo autor especialmente para este artigo.

** Bacharel pela Musikhochschule Köln, Alemanha (1991), Mestre em Filosofia pela Pontifícia Universidade Católica do Rio Grande do Sul (2002) e Doutor em Filosofia pela Pontifícia Universidade Católica do Rio Grande do Sul (2004), com Estágio de Pesquisa na Universidade Karl Eberhard, de Tübingen (Alemanha). Atualmente é professor adjunto da Pontifícia Universidade Católica do Rio Grande do Sul e da Faculdade IDC. Atua na área de Filosofia, com ênfase em Estética, principalmente em temas interdisciplinares de Música e Filosofia. Realizou (2009/2010) estágio de pesquisa (PósDoutorado) em Ética na Mídia, na Technische Universität Kaiserslautern, Alemanha.

\begin{tabular}{|l|l|l|l|l|l|}
\hline Teocomunicação & Porto Alegre & v. 45 & n. 1 & p. $85-105$ & jan.-abr. 2015 \\
\hline
\end{tabular}




\section{ABSTRACT}

In the Commandments, God prohibits Mankind both to create images and to take His name in vain. There are, thus, strict limits separating the sacred and the human realms. This paper aims to examine parallels and dissents between the thinking of two scholars who approached that issue from different perspectives: the neo-Marxist Jew philosopher Theodor Adorno and the Lutheran theologian Eberhard Jüngel.

Keywords: Negative Dialectics. Ineffability of God. Non-identical. Name of God.

Todos os que te procuram te tentam. E te prendem, logo que te encontram, a imagem e gesto. ${ }^{1}$

RAINER MARIA RILKE

\section{Introdução}

Eberhard Jüngel (1934) e Theodor Adorno (1903-1969) tinham em comum a desconfiança para com o ativismo político. Jüngel nasceu e cresceu na extinta República Democrática Alemã, um país comunista, o que contribuiu para sua crítica à teologias da práxis ou comprometida com projetos políticos. Para Jüngel, a genuína dimensão política da fé teria de se apoiar apenas na verdade e na liberdade. Adorno, que sofreu a perseguição do regime hitlerista, sempre defendeu a ênfase na análise teórica da sociedade, explicitada em seu livro Notas marginais sobre teoria e práxis. Para ele, o ato de pensar como autorreflexão [Selbstbesinnung] seria determinante para revelar deformações nas relações humanas, e poderia servir para transformar a política e a sociedade como um todo (FILLION, 2012, p. 41).

Um dos temas centrais da obra adorniana é a reificação do mundo por obra da racionalidade. Adorno aborda essa questão por diferentes vieses: estético (Teoria Estética e Filosofia da nova música), ético (Minima moralia), epistemológico (Dialética Negativa) e teológico (em vários ensaios curtos). Seu pensamento teológico, ainda que não se mostre evidente como na obra de seu colega Walter Benjamin, pode ser encontrado de forma fragmentária em todos seus escritos. No ensaio

\footnotetext{
1 Alle, welche dich suchen, versuchen dich. Und die, so dich finden, binden dich an Bild und Gebärde (RILKE, Rainer Maria: Das Stunden-Buch, Leipzig: Insel 1912, S. 59-60).
} 
Fragmento Sacro (Sakrales Fragment), Adorno examina a oposição dramático-musical dos personagens Moisés e Aarão, da ópera homônima de Arnold Schönberg. Ali, um Moisés recalcitrante e obstinado defensor do Segundo Mandamento entra em conflito com um Aarão hábil construtor de metáforas, com a ajuda das quais comove e ganha para si os corações e mentes do povo de Israel. A proibição mosaica e a ópera de Schönberg são expressões especulares de uma questão teológica clássica, a da relação de Deus com o mundo. A Dialética Negativa adorniana trata essa questão com a ajuda da tradição teológica: para evitar a violência do sujeito sobre o objeto, Adorno enuncia um novo imperativo categórico, em que a superação do imperativo original kantiano tem o propósito de evitar a barbárie da razão, "evitar que se repita Auschwitz". ${ }^{2}$ Para isso, seria necessário que fosse respeitado o caráter único de cada ente, incluída aí sua absoluta não identidade. O passo inicial para isso seria a recusa da inserção dos objetos em categorias reificadoras.

A teologia de Eberhard Jüngel procura conciliar as noções de Deus e de história. Distanciando-se da tradição atemporal da metafísica, Jüngel afirma que "o Ser de Deus é sua história de amor". E toda história de amor, ressalta Jüngel, precisa ser contada. A teologia jüngeliana, portanto, é uma hermenêutica da palavra da cruz: "O sacerdócio profético de Jesus Cristo desvela o ser Jesus Cristo em sua obra de reconciliação como um acontecimento da linguagem"3 (JÜNGEL, 1967, p. 13). Deus, para Jüngel, é amor que se manifesta na história - e deve-se acrescentar, para a boa compreensão em português, também na estória (em alemão a mesma palavra [Geschichte] pode designar a história como fluxo temporal ou a narrativa de acontecimentos). $\mathrm{O}$ amor de Deus se manifesta na estória - porque é na palavra da cruz que Ele fala à humanidade - e na história - porque essa palavra precisa ser levada adiante, no tempo. Chouraqui (1997) aponta que, no versículo 18 de João (Ninguém jamais viu a Deus: o Filho único que está voltado para o seio do Pai, este o deu a conhecer.), o verbo grego exegeisthaï (de onde a palavra exegese, em português) tem, como sentidos derivados,

2 Hitler hat den Menschen im Stande ihrer Unfreiheit einen neuen kategorischen Imperativ aufgezwungen: ihr Denken und Handeln so einzurichten, daß Auschwitz nicht sich wiederhole, nichts Ähnliches geschehe. [Band 6: Negative Dialektik. Jargon der Eigentlichkeit: Dritter Teil: Modelle. Digitale Bibliothek Band 97: Theodor W. Adorno: Gesammelte Schriften, S. 3422 (vgl. GS 6, S. 358)]

3 Das prophetische Amt Jesu Christi enthüllt das Sein Jesu Christi in seinem Versöhnungswerk als Sprachereignis. 
"explicar, relatar", e, especialmente, "revelar" (os mistérios divinos). Cristo, portanto, procederia à exegese do Pai (só o Filho único de Deus pode conduzir a Ele) de quem seria a única porta de entrada, conforme suas palavras $(\mathrm{Jo}, 14,5),{ }^{4}$ o que confirmaria a tese de Jüngel de Deus como amor e, ao mesmo tempo, como estória a ser narrada.

O nome de Deus, o impronunciável, assinala, na Bíblia, uma separação das esferas do divino e do humano. Dizer o Nome seria inseri-lo em uma ordem finita, uma ordem criada pelo dono do Nome: seria objetificá-lo. Ao tentar mediar o Absoluto, a linguagem insere o Nome dentro de um conceito, produzindo, a partir Dele, uma formulação cognoscível, mas falsa: Hic Deus. Pronunciar o Nome, assim, seria uma forma de negar a necessidade da revelação. Este artigo fará uma aproximação da Dialética Negativa de Adorno e do estudo de Eberhard Jüngel acerca da dizibilidade de Deus, Zur Sagbarkeit Gottes, em seu livro Gott als Geheimnis der Welt. Isso será feito por meio de uma leitura comparada dos textos de Adorno e Jüngel, com o propósito de demonstrar que o Bildverbot - a interdição veterotestamentária - é parte fundamental tanto da ética micrológica adorniana quanto do projeto de Jüngel de pensar Deus como amor. Este artigo pretende, também, demonstrar que os dois autores trabalham, ainda que de forma crítica, com categorias originadas da filosofia da história de Hegel. Finalmente, demonstra que a negatividade - tanto na filosofia quanto na teologia ainda é capaz de oferecer uma resposta para a questão do direito de cada objeto - cada não idêntico, no jargão da Teoria Crítica - de receber uma categoria total e unicamente sua. A realização desse projeto começa pelo nome de Deus e vai, na busca da sagrada individualidade de cada ente, até o nome de todas as coisas.

\section{Dialética contra a dialética}

A Escola de Frankfurt teve como projeto criticar o Iluminismo. O valor positivo por excelência da sociedade moderna, a razão, passou a ser suspeita de ser também a causa das deformações morais dessa sociedade. Esse aspecto dialético da inteligência - capaz de libertar

\footnotetext{
4 “Tomás de Aquino ensinará que Iéshoua é o caminho por causa de sua humanidade, a verdade e a vida em função de sua divindade. O tema do caminho é central na Bíblia“ (CHOURAKI, p. 222), imagem que também corrobora a tese de Jüngel de Deus como Ser em devir (ver JÜNGEL, E.: Gottes Sein ist im Werden. Verantwortliche Rede vom Sein Gottes bei Karl Barth, eine Paraphrase. Tübingen, Mohr Verlag, 1967).
} 
da ignorância e da superstição, mas, ao mesmo tempo, de criar novas mitologias no seio de um mundo tecnológico tendente à barbárie - seria, para pensadores como Adorno, Benjamin, Marcuse e Horkheimer, um componente contraditório e inextirpável da condição humana. Em sua Dialética do Esclarecimento, Adorno e Horkheimer localizam o nascimento dessa contradição não na França do século XVIII, mas no primeiro ato racional do homem macaco, no Paleolítico. Ao reprimir o desejo de fruição imediata de prazer em favor de outros valores prevenção, segurança, expectativa de fruir mais prazer no futuro - o homem macaco teria, segundo Adorno e Horkheimer, realizado a primeira ação teleológica e inteligente da história. A partir daí, esse mecanismo de renúncia passaria a condicionar o raciocínio humano que nascia e a separar, em campos antagônicos, erotismo e civilização.

$\mathrm{Na}$ Dialética Negativa, Adorno examina a principal ferramenta da ratio, o conceito, na forma de expressão da linguagem. Conclui que dar nome às coisas é parte da violência que o eu subjetivo exerce sobre tudo que é externo a si: um nome, afirma Adorno, não informa nada sobre um objeto, pois não é o objeto que se expressa. ${ }^{5}$ A identificação de conceito e objeto é pressuposto da metafísica, para a qual a igualdade é possível porque acredita que a linguagem seria capaz de abranger todos os aspectos de um objeto. A fórmula de Francis Bacon, scientia potentia est (Meditationes Sacrae), expressa o credo otimista de que o sujeito tem condições de chegar à coisa em si. O resultado dessa crença foi um processo de reificação dos objetos externos à ratio, os quais precisam, assim, alinhar-se conforme a taxonomia ditada pela civilização. ${ }^{6}$ A intenção da Dialética Negativa, contudo, não é descartar

5 Denn der Name ist keine Mitteilung von einem Gegenstand. [Band 18: Musikalische Schriften V: Über das gegenwärtige Verhältnis von Philosophie und Musik. Digitale Bibliothek Band 97: Theodor W. Adorno: Gesammelte Schriften, S. 14534 (vgl. GS 18, S. 155)]

6 A tradição filosófica conhece desde Heráclito a crítica da linguagem, ou, no mínimo, o questionamento acerca dos limites da dizibilidade das coisas. O fragmento heraclitiano B108, "De quantos ouvi discursos, ninguém chega a compreender que o saber está

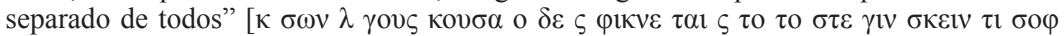
$v \sigma \tau 1, \pi \nu \tau \omega \nu \kappa \varepsilon \chi \omega \rho \iota \sigma \mu \nu o v]$, aborda a relação entre o estatuto ontológico do universal discurso e os muitos discursos que Heráclito escutou. $\mathrm{O}$ discurso, na condição de não idêntico, resiste à inserção na taxonomia dos discursos - a sintaxe o destituiria de sua condição de universal. Para Schüler (2000), "se lográssemos surpreender o núcleo do indizível, proferiríamos a última palavra, que decretaria o fim de todo falar. O saber é decididamente mais do que o dito. $\mathrm{O}$ que nos discursos sábios seduz, brilha como reflexo do saber ausente. O oculto é muito mais do que o que se mostra" (SCHÜLER, Donaldo: Heráclito e seu (dis)curso. Porto Alegre: L\&PM, 2000). 
a Lógica: Adorno visa livrar-se do caráter afirmativo da dialética, mas sem sacrificar o rigor investigativo; um dos objetivos é o desdobramento de seu título paradoxal. ${ }^{7}$ Rigor, aqui, não deve ser confundido com positividade. Ao contrário da metafísica, que afirma só haver rigor em objetos retirados da corrosão do tempo, o pensamento neo-hegeliano da Escola de Frankfurt quer afirmar a existência de rigor no efêmero.

A expressão dialética negativa atenta contra a tradição. Já em Platão a dialética acreditava que, por meio da negação, era possível chegarse à positividade. A figura de uma negação da negação deu nome ao que, depois, se tornou moralismo. ${ }^{8}$

Ao descartar o princípio de identidade, o pensamento adorniano vai ao encontro do clássico problema teológico da indizibilidade de Deus. No Terceiro Mandamento (Ex. 20.7), a proibição da mímesis, expressa no Segundo Mandamento (Ex. 20.4) é estendida à pronúncia do Nome. Se, por um lado, pronunciar o nome de Deus é uma contradição em termos (não seria possível inserir o Nome na ordo que foi criada pelo dono do Nome), por outro, a filosofia precisaria rever a ferramenta que utiliza quando conceitua objetos e valida a equação conceito = coisa . Esse projeto guarda semelhança com a tradição kantiana: a crítica visa reformular a dialética, não destruí-la. Para escapar da totalidade hegeliana, a dialética negativa precisaria ser assistemática, pensa Adorno - daí a contradição [Widerspruch] à norma da adaequatio:

Inicialmente, seu nome não diz outra coisa senão que os objetos não se realizam em seus conceitos e que esses entram em contradição com a norma convencional da adaequatio. A contradição não é aquilo em que o idealismo absoluto de Hegel precisou inevitavelmente transfigurá-la: não é nenhuma essencialidade heraclitiana. Ela é o

7 Das Buch möchte Dialektik von derlei affirmativem Wesen befreien, ohne an Bestimmtheit etwas nachzulassen. Die Entfaltung seines paradoxen Titels ist eine seiner Absichten. [Band 6: Negative Dialektik. Jargon der Eigentlichkeit: Vorrede. Digitale Bibliothek Band 97: Theodor W. Adorno: Gesammelte Schriften, S. 2825 (vgl. GS 6, S. 9)]

8 Die Formulierung Negative Dialektik verstößt gegen die Überlieferung. Dialektik will bereits bei Platon, daß durchs Denkmittel der Negation ein Positives sich herstelle; die Figur einer Negation der Negation benannte das später prägnant [Band 6: Negative Dialektik. Jargon der Eigentlichkeit: Vorrede. Digitale Bibliothek Band 97: Theodor W. Adorno: Gesammelte Schriften, S. 2825 (vgl. GS 6, S. 9)]. 
sinal da não verdade da identidade, da realização daquilo que é concebido no conceito. ${ }^{9}$

A Dialética Negativa quer fazer uma crítica interna à metafísica; nela, como em vários outros escritos, começando com sua tese sobre Kirkegaard, Adorno aborda questões teológicas. Para Hullot-Kentor (Apud Kaufmann), o pensamento teológico está sempre presente, logo abaixo da superfície dos escritos de Adorno, e perpassa todas as suas obras. A proibição da mímesis e da pronúncia do Nome pode ser considerada, no conjunto da obra adorniana, um modelo para a crítica à racionalidade reificadora.

Eberhard Jüngel, em sua obra Gott als Geheimnis der Welt (Deus como mistério do mundo), examina o problema da dizibilidade de Deus. ${ }^{10}$ Ao adjetivar Deus como mistério, Jüngel retoma o significado clássico dessa palavra: myein (em grego $=$ fechar) referia-se, no contexto dos cultos mistéricos, à obrigação de os iniciados fecharem os olhos e a boca. A relação com objetos externos, assim, devia prescindir da visão, aqui entendida como metáfora do conhecimento claro, racional, e mediado por conceitos. ${ }^{11} \mathrm{O}$ ato de fechar a boca referir-se-ia, ainda, à interdição do logos, isto é, à interdição da expressão verbal do conceito mediador. O conhecimento mistérico é, por extensão, um conhecimento imediato. Para Jüngel, falar de Deus pressupõe a noção da diferença do que seja falar Dele correta ou incorretamente, diferença que estaria baseada no falar responsável [verantwortlich] ou não. Esse "responsável" precisa, aqui, ser entendido como aquilo que responde a uma palavra [Wort]. O vocábulo alemão verantwortlich, construído em torno do radical - wort

9 Ihr Name sagt zunächst nichts weiter, als daß die Gegenstände in ihrem Begriff nicht aufgehen, daß diese in Widerspruch geraten mit der hergebrachten Norm der adaequatio. Der Widerspruch ist nicht, wozu Hegels absoluter Idealismus unvermeidlich ihn verklären mußte: kein herakliteisch Wesenhaftes. Er ist Index der Unwahrheit von Identität, des Aufgehens des Begriffenen im Begriff. [Band 6: Negative Dialektik. Jargon der Eigentlichkeit: Einleitung. Digitale Bibliothek Band 97: Theodor W. Adorno: Gesammelte Schriften, S. 2833 (vgl. GS 6, S. 16-17)]

${ }^{10} \mathrm{O}$ livro de Jüngel defende a tese de que o conhecimento de Deus é possível, mas tem de ser um conhecimento que se abstenha do caráter reducionista da ciência humana - seria necessário, então, um conhecimento mistérico. Além da questão da dizibilidade de Deus, Jüngel aborda também a morte de Deus como expressão da aporia da moderna filosofia da religião e as questões da pensabilidade e da humanidade de Deus. Ver JÜNGEL, Eberhard: Gott als Geheimnis der Welt. Tübingen, J.C.B. Mohr, 1977.

11 "A fé é uma posse antecipada do que se espera, um meio de demonstrar as realidades que não se veem" $(H b, 11.1)$. Para Jüngel, a fé deseja pensar Deus; entende-se que este seja um pensar não teleológico e iluminista, o pensar Deus que a fé deseja seria um pensar místico. 
[palavra], denota uma relação análoga à do português, que é aquela entre o radical $($ Wort $=$ palavra $)$ e o vocábulo aglutinante ver + ant + wortlich = responsável no sentido de "dar resposta a uma palavra". Em português, a ênfase está no ato de responder que o responsável desempenha: ele é responsável ao responder. Responder a quê? Aqui, é necessária a ajuda do alemão: responder a uma palavra [Wort], que pode denotar frase, discurso, questão, em última análise, logos. Se a humanidade é ou não capaz dessa dizibilidade de Deus, dependeria de esse "dizer de Deus" cumprir o objetivo a que se destina, isto é, não ter como resultado o efeito contrário ao pretendido. E, para isso, o falar de Deus precisaria ser um falar responsável [verantwortlich] de Deus, precisaria responder à palavra, que, em última análise, é a palavra de Deus no Mandamento que proíbe tomar seu nome em vão.

Assim, a diferenciação fundamental entre um emprego correto e variado e um abuso não propriamente pobre de variedade da palavra "Deus" é parte inequívoca do falar de Deus. É possível maltratar essa palavra de forma refinada ou grosseira, é possível mesmo tomar o nome de Deus "em vão". Em que consiste esse abuso? [...] O abuso da palavra "Deus" se dá com certeza quando se atinge o contrário daquilo que reconhecemos como um falar responsável de Deus. ${ }^{12}$

A solução sugerida por Jüngel é análoga à proposta da negatividade da dialética adorniana: se, para Adorno, conceituar um objeto tem sempre um potencial reducionista e predador por parte da ratio, Jüngel defende a dizibilidade de Deus pelo homem na medida em que esse dizer permite que Deus mesmo se expresse nesse ato: "O falar humano de Deus merece, então, ser chamado de responsável quando não pretende outra coisa senão deixar que Deus mesmo tome a palavra". ${ }^{13}$

${ }_{12}$ Zur Rede von Gott gehört daher unabweisbar die Grundunterscheidung von Rechten vielvältigen Gebrauch und einem ebenfalls nicht gerade abwechslungsarmen Missbrauch des Wortes "Gott". Man kann dieses Wort in grober und feiner Weise misshandeln, kann selber den Namen Gottes , unnützlich führen“. Worin besteht solcher Missbrauch? [...] Missbrauch des Wortes Gott liegt auf jeden Fall dann vor, wenn wenn dadurch das Gegenteil dessen erreicht wird, was wir als verantwortlich Rede von Gott erkannt haben (JÜNGEL, p. 308).

${ }_{13}$ Menschliches Reden von Gott verdient aber dann verantwortlich gennant zu werden, wenn es nichts anderes intendieren will, als Gott selbst zu Wort kommen zu lassen (JÜNGEL, p. 308). 


\section{Deus: o objeto como sujeito de si}

A questão da violência do sujeito contra o objeto é abordada a partir de perspectivas diferentes em Adorno e Jüngel. Ambos os autores, porém, concluem de forma utópica, aporética. Jüngel propõe que Deus é dizível quando é Ele quem fala pelo sujeito. É possível identificar aqui traços da proibição do Gênesis de comer o fruto da árvore do conhecimento do bem e do mal (Gen. 2, 17): o conhecimento seria possível, mas não pela via da ciência humana. Falar de Deus seria possível, mas esse falar - esse logos - não poderia ser humano. Apenas ignorando-se o princípio parmenídico do terceiro excluso seria possível superar esses impasses. Adorno aponta uma solução: a racionalidade que descarrega sua violência contra o objeto pode ser convertida em racionalidade boa, desde que "mediada pela fantasia". Só a fantasia, na medida em que é desprovida de telos, escaparia à pulsão de dominação da natureza que permeia todo ato racional humano. Daí a importância que a estética assume na ética e na epistemologia de Adorno: a obra de arte autônoma seria capaz de sintetizar racionalidade e fantasia sem que nenhuma perdesse sua legitimidade.

O juízo, segundo o qual algo seja de um modo tal, rejeita potencialmente que a relação de seu sujeito e de seu predicado seja diversa da que é expressa no juízo. As formas de pensamento querem ir além daquilo que está meramente disponível, além daquilo que está "dado". A ponta que o pensamento dirige contra o seu material não é apenas a dominação espiritualizada da natureza. Quando o pensamento pratica violência contra aquilo sobre o que realiza sua síntese, procura um potencial que dorme em seu oponente e obedece, ao mesmo tempo, inconscientemente, à ideia de indenizar, com os pedaços, aquilo que ele mesmo perpetrou; a filosofia, inconscientemente, ganha consciência disso. ${ }^{14}$

${ }^{14}$ Das Urteil, etwas sei so, wehrt potentiell ab, die Relation seines Subjekts und seines Prädikats sei anders als im Urteil ausgedrückt. Die Denkformen wollen weiter als das, was bloß vorhanden, "gegeben « ist. Die Spitze, die Denken gegen sein Material richtet, ist nicht einzig die spirituell gewordene Naturbeherrschung. Während das Denken dem, woran es seine Synthesen übt, Gewalt antut, folgt es zugleich einem Potential, das in seinem Gegenüber wartet, und gehorcht bewußtlos der Idee, an den Stücken wieder gutzumachen, was es selber verübte; der Philosophie wird dies Bewußtlose bewußt. [Band 6: Negative Dialektik. Jargon der Eigentlichkeit: Einleitung. Digitale Bibliothek Band 97: Theodor W. Adorno: Gesammelte Schriften, S. 2856 (vgl. GS 6, S. 30-31)] 
Jüngel também encontra uma solução para o impasse: falar de Deus é possível quando esse falar corresponder [entsprechen] a Ele. Portanto, meramente falar de Deus [sprechen] não é possível; mas, se esse falar corresponder [entsprechen] a Deus, na medida em que permitir que Deus seja o sujeito desse ato de fala, o dizer é lícito, porque não tem como telos um conhecimento científico humano do objeto (do objeto Deus, que, agora, é objeto e é também sujeito desse falar). Ao converterse em sujeito do ato de fala que tem por objetivo falar Dele mesmo, Deus corresponde [entspricht] a Si mesmo. E, ao corresponder-Se, Sua fala é responsável [verantwortlich], ela atende à sua palavra, atende ao Terceiro Mandamento.

O falar de Deus é, então, responsável, só quando pretende corresponder a Deus. E ele corresponde a Deus na medida em que permite que Deus demande. O falar humano é correspondente a Deus quando faz com que Deus fale de forma que Ele seja o sujeito desse ato de fala. ${ }^{15}$

Mas, para que Deus se faça sujeito do falar humano, Jüngel acredita que seja necessário pensar Deus: "Quem quiser falar responsavelmente de Deus, tem de pensar Deus". ${ }^{16} \mathrm{O}$ procedimento pode ser esquematizado desta forma:

\section{PENSAR DEUS $=>$ PERMITIR QUE DEUS SE TORNE SUJEITO DO FALAR DE DEUS}

Há uma aparente contradição, ao preconizar-se, primeiramente, um falar de Deus que seja imediato - e, para isso, tenha de se contornar o obstáculo do conceito -, e, em seguida, um pensar Deus [Gott denken] como condição prévia para esse ato de fala. O falar imediato pressupõe um falar que não necessita de mediação do conceito. E, sem conceito, não se poderia chamar a esse ato prévio de "pensar" Deus. Essa contradição é a mesma que Adorno tenta resolver por meio da negatividade de sua dialética: “... através do deserto de gelo

\footnotetext{
${ }^{15}$ Verantwortlich ist die Rede von Gott also erst dann, wenn sie darauf bedacht ist, Gott zu entsprechen. Und sie entspricht Gott darin, dass sie Ihn kommen lässt. Gott entsprechend ist diejenige menschliche Rede, die Gott so zur Sprache bringt, dass sie Ihn das Subjekt dieses Sprachvorganges sein lässt (Jüngel p. 308).

${ }^{16}$ Wer verantwortlich von Gott reden will, muss Gott denken (Jüngel p. 309).
} 
da abstração, atingir concisamente um filosofar concreto". ${ }^{17}$ Para atravessar o "deserto de gelo da abstração", não é permitido se fixar em conceitos. O objetivo é chegar a um conhecimento conciso. ${ }^{18}$ Esse conhecimento, acredita Adorno, não equivale à totalidade. A totalidade, para ele, seria parte da mitologia do idealismo, que produziu um sistema, o hegeliano, em que apenas o todo é verdadeiro - assim, antes do movimento dialético produzir uma síntese [Aufhebung], não seria possível conhecer. A Dialética Negativa quer tratar do que está fora da atração da totalidade, ela é fruto da necessidade de um reencontro com a finitude.

[...] a dialética negativa [...] poderia ser chamada de antissistema. Com meios logicamente consistentes, ela se esforça por colocar, no lugar do princípio de unidade e do domínio totalitário do conceito supraordenado, a ideia daquilo que estaria fora da atração de tal unidade. ${ }^{19}$

Para isso, o primeiro passo seria inverter a máxima de Hegel " $\mathrm{O}$ todo é o verdadeiro" ${ }^{20}$ para "O todo é o não verdadeiro". ${ }^{21}$ A necessidade de recuperar a finitude é consequência, afirma Adorno, do fracasso da filosofia idealista. Como o Espírito [Geist] não se encontrou consigo mesmo, ainda existem história e tempo; a filosofia não se realizou, e

${ }^{17}[\ldots]$ durch die Eiswüste der Abstraktion hindurch, um zu konkretem Philosophieren bündig zu gelangen [Band 6: Negative Dialektik. Jargon der Eigentlichkeit: Vorrede. Digitale Bibliothek Band 97: Theodor W. Adorno: Gesammelte Schriften, S. 2826 (vgl. GS 6, S. 9)].

18 Adorno, aqui, inverte o pensamento de Plotino, em sua Enéada I. Nela, Plotino faz uma analogia da viagem de Ulisses para Ítaca com o filósofo que busca o conceito. Cada parada da Odisseia (os lotófagos, Polifemo, Circe, Calipso etc.) é identificada com a tentação de fixar-se em objetos, em vez de seguir rumo à abstração, ao conceito. Assim, se Ulisses tivesse se conformado em permanecer na ilha de Circe, e acreditasse que aquela seria sua "cara pátria" (ULLMANN, p. 23), nunca chegaria à sua verdadeira pátria, Ítaca. A imagem do viajante que não pode se deter sob pena de nunca alcançar o destino é retomada por Adorno em uma versão antimetafísica: como um conceito não pode exprimir todas as dimensões de existência do objeto, é necessária uma dialética que não apresente uma síntese final.

${ }^{19}$ [...] so könnte die Negative Dialektik [...] Antisystem heißen. Mit konsequenzlogischen Mitteln trachtet sie, anstelle des Einheitsprinzips und der Allherrschaft des übergeordneten Begriffs die Idee dessen zu rücken, was außerhalb des Banns solcher Einheit wäre. [Band 6: Negative Dialektik. Jargon der Eigentlichkeit: Vorrede. Digitale Bibliothek Band 97: Theodor W. Adorno: Gesammelte Schriften, S. 2826 (vgl. GS 6, S. 10)]

${ }^{20}$ Das Ganze ist das Wahre (HEGEL: Phenomenologie des Geistes, Vorrede).

${ }^{21}$ Das Ganze ist das Unwahre (ADORNO: Minima Moralia, p. 55). 
fracassou a tentativa da metafísica de pensar o mundo fora da corrosão do tempo. Daí a importância da revalorização epistemológica da dimensão do finito. Esse é o sentido da crítica a Hegel contida no parágrafo inicial da Dialética Negativa:

A filosofia, que um dia pareceu ultrapassada, mantém-se viva porque se perdeu o instante de sua realização. O juízo sumário de que ela tivesse simplesmente interpretado o mundo e de que teria também, por resignação diante da realidade, se deformado em si, torna-se um derrotismo da razão depois que a transformação do mundo fracassou. ${ }^{22}$

\section{Pensar Deus}

Assim como em Adorno, a proposta de Jüngel, de pensar-se Deus como condição preliminar para que Ele se torne o sujeito do ato de fala, equivale a um pensamento que evita fixar-se em conceitos (o "deserto de gelo da abstração"). O problema que se apresenta agora é o seguinte: se o Nome expressa a sacralidade de Deus em um nível tal que a exigência de não pronunciá-lo é superior à necessidade humana de nomeá-lo, o pensar humano de Deus precisaria esquivar-se a todo pensamento que tenha sido anteriormente pensado. Caso contrário, fixar-se-ia em modelos já esclerosados, o que equivaleria a tentar inserir o Nome dentro de um conceito no qual Ele não caberia; em suma, equivaleria a "tomar o nome de Deus em vão". Desse modo, pensar Deus precisa, para Jüngel, ser um pensamento sempre à frente, precisa ser um pensamento sempre novo, "mesmo quando esse pensamento novo for completamente idêntico a um pensamento de Deus constante da tradição" (JÜNGEL, p. 309).

Essa tarefa consiste, igualmente, em pensar o pensamento tradicional sobre Deus cada vez de forma nova, quer seja, pensar Deus em um pensamento novo de Deus, $[\ldots]$ mesmo quando $[\ldots]$ esse pensamento

\footnotetext{
${ }^{22}$ Philosophie, die einmal überholt schien, erhält sich am Leben, weil der Augenblick ihrer Verwirklichung versäumt ward. Das summarische Urteil, sie habe die Welt bloß interpretiert, sei durch Resignation vor der Realität verkrüppelt auch in sich, wird zum Defaitismus der Vernunft, nachdem die Veränderung der Welt mißlang. [Band 6: Negative Dialektik. Jargon der Eigentlichkeit: Einleitung. Digitale Bibliothek Band 97: Theodor W. Adorno: Gesammelte Schriften, S. 2830 (vgl. GS 6, S. 15)]
} 
novo for completamente idêntico a um pensamento de Deus constante da tradição. ${ }^{23}$

Adorno, em sua Filosofia da nova música (1948), dedica-se a esse problema: como recuperar as constelações [imagens] musicais primevas [musikalische Urbilder], as únicas infensas a cooptação por forças regressivas? A solução é análoga à de Jüngel: a categoria do "progresso" [Fortschritt] possibilitaria o resgate: "A verdadeira intenção do progresso na música é arrancar à muda eternidade as constelações [imagens] musicais primevas". ${ }^{24}$

A obra de arte, em Adorno, é o lugar onde o ético se abrigou depois de não ter se realizado no mundo. A arte seria o domínio do não idêntico [Nichtidentisches], aquilo que não é igual a mais nada, aquilo que possui uma categoria apenas sua. $\mathrm{O}$ Nome seria o não idêntico adorniano por excelência. E para que o não idêntico que existe preservado dentro da obra de arte possa resistir à cooptação pela regressão e à violência do conceito, ele precisa ser constituído de material que incorpore os meios técnicos mais avançados à disposição: "Progresso não significa outra coisa senão sempre tomar o material no estágio mais avançado de sua dialética histórica". ${ }^{25}$ A resistência do objeto em deixar-se apreender pelo conceito é o contraponto, acredita Adorno, da história da dominação da natureza pelo homem: as ciências naturais classificaram o mundo em categorias para, em seguida, agredilo. A história, entendida hegelianamente como o progresso do Espírito [Geist], tem sua expressão na metáfora bíblica da queda e da expulsão do paraíso: uma vez envenenada a natureza e assassinadas as criaturas, tudo subsistirá meramente como conceito nos livros.

Os arcabouços conceituais nos quais, segundo costume filosófico, o todo deveria poder ser alocado, assemelham-se, em vista da sociedade desmedidamente expandida e dos progressos do conhecimento

${ }^{23} \mathrm{Zu}$ dieser Arbeit gehört gleichermassen, sich den überlieferten Gottesgedanken zu jeder Zeit neu, beziehungsweise Gott in einem neuen Gottesgedanken zu denken. [...] selbst dan [...] wenn [...] der überlieferte Gotesgedanke mit dem von neuem erarbeiteten Gottesgedanken völling identisch sein sollte (JÜNGEL p. 309).

${ }^{24}$ Der sprachlosen Ewigkeit die musikalischen Urbilder zu entreissen ist die wahre Intention des Fortschrittes von Musik (ADORNO, Reaktion und Fortschritt, in ADORNO, Theodor, und KRENEK, Ernst: Briefwechsel, 179).

${ }^{25}$ Fortschritt heisst nichts anderes als je und je das Material auf der fortgeschrittensten Stufe seiner geschichtlichen Dialektik ergreifen (ADORNO, Theodor, KRENEK, Ernst: Briefwechsel, 177). 
positivo da natureza, aos restos da simples economia de mercado em meio ao capitalismo industrial tardio. A desproporção entre o poder e toda forma de espírito tornou-se tão grande que as tentativas, inspiradas pelo próprio conceito de Espírito, de compreender o poder superior, são em vão. $\mathrm{O}$ desejo de fazê-lo denota uma ambição de poder, a qual é refutada por aquilo que deveria compreender. ${ }^{26}$

Se a solução de Adorno - o máximo progresso do material como forma de recuperar a primordialidade do objeto - for transferida para o problema do Nome, tem-se a fórmula de Jüngel: "Deus pode apenas ser pensado como Aquele que tem de ser pensado sempre de maneira nova". ${ }^{27}$ Deus precisa, portanto, ser pensado sempre de novo; qualquer repetição faria, para Jüngel, com que o pensamento e o Nome caiam num processo dialético, em que se instauraria o imperativo de superar a oposição entre tese e antítese (Nome versus conceito do Nome, ou Nome versus nome do Nome). Seria equivocado, assim, acreditar que esse pensamento novo possa acontecer a partir de um conceito daquilo que seja o Nome: conceitos são, na tradição ocidental, resultado de uma síntese dialética. Nela, tese e antítese são superadas e guardadas [aufgehoben], mas, de fato, desaparecem; continuam a existir apenas como memória daquilo em que resultaram: a síntese de sua extinta oposição. Para Jüngel, o pensar sempre renovado tem duas consequências: (1) responde [antwortet] à palavra de Deus [o Nome] sem que esta se manifeste apenas depois de ser pensada e (2) propicia com que Deus esteja presente nesse pensamento: "A responsabilidade teológica do pensar consiste em responsabilizar-se por uma palavra que não se manifesta apenas ulteriormente a Deus como Aquele em que se pensa, e sim está presente naquilo em que Deus está presente

\footnotetext{
${ }^{26}$ Die begrifflichen Gehäuse, in denen, nach philosophischer Sitte, das Ganze sollte untergebracht werden können, gleichen angesichts der unermeßlich expandierten Gesellschaft und der Fortschritte positiver Naturerkenntnis Überbleibseln der einfachen Warenwirtschaft inmitten des industriellen Spätkapitalismus. So unmäßig ist das mittlerweile zum Topos herabgesunkene Mißverhältnis zwischen Macht und jeglichem Geist geworden, daß es die vom eigenen Begriff des Geistes inspirierten Versuche, das Übermächtige zu begreifen, mit Vergeblichkeit schlägt. Der Wille dazu bekundet einen Machtanspruch, den das zu Begreifende widerlegt. [Band 6: Negative Dialektik. Jargon der Eigentlichkeit: Einleitung. Digitale Bibliothek Band 97: Theodor W. Adorno: Gesammelte Schriften, S. 2831 (vgl. GS 6, S. 15-16)]

${ }^{27}$ Gott kann nur als der stets neu zu Denkende gedacht werden (Jüngel p. 309).
} 
como Deus". ${ }^{28}$ Fica, assim, demonstrado que a teologia hermenêutica de Eberhard Jüngel trabalha com categorias históricas - ou categorias a ela correlatas, como as de progresso e tempo - tanto quanto o neomarxista Adorno. Jüngel admite-o explicitamente: "A teologia está sempre se referindo à história". ${ }^{29}$ Em seu livro O Ser de Deus está no Devir [Gottes Sein ist im Werden. Verantwortliche Rede vom Sein Gottes bei Karl Barth, eine Paraphrase], ele apresenta sua versão de uma metafísica do devir.

Adorno expressa em uma fórmula neo-hegeliana sua compreensão da ligação entre história e conhecimento: "No material, porém, há história sedimentada". ${ }^{30}$ Ela embasa o fundamento hegeliano - mesmo que crítico a Hegel - de sua tese de que o não idêntico, para escapar à regressão, tem de ser constituído por material que seja "história sedimentada", isto é, material que não tenha esgotado sua primordialidade pelo uso repetido. No trecho a seguir, pode-se observar novamente como o pensamento neo-hegeliano e neomarxista de Adorno apresenta, como notou Hullot-Kentor, "logo abaixo da superfície“, um componente teológico: "As exigências do material para com o sujeito provêm muito mais do fato de o próprio material ser espírito sedimentado, socialmente pré-formado através da consciência dos homens". 31

\section{In Paradiso}

A questão de uma possível recuperação da primordialidade dos objetos remete, na teologia cristã, à queda, ao pecado original. Walter Benjamin, aponta Kaufmann, emprega a metáfora bíblica do paraíso quando se refere a um utópico estado pré-dialético da relação entre sujeito e objeto: lá, não haveria ainda tensão entre palavra e seu significado:

${ }^{28}$ Die theologische Verantwortlichkeit des Denkens besteht im verantworten eines Wortens, das zu Gott als dem zu Denkenden nicht erst nachträglich hinzutritt, sondern in dem Gott als Gott anwesend ist (Jüngel p. 311).

${ }^{29}$ Theologie ist so immer auf Geschichte bezogen (Jüngel p. 311).

${ }^{30}$ Im Material aber ist Geschichte sedimentiert. [Band 10: Kulturkritik und Gesellschaft I/II: Ohne Leitbild. Digitale Bibliothek Band 97: Theodor W. Adorno: Gesammelte Schriften, S. 7886 (vgl. GS 10.1, S. 299)]

${ }^{31}$ Die Forderungen, die vom Material ans Subjekt ergehen, rühren vielmehr davon her, dass das 'Material' selber sedimentierter Geist, ein gesellschaftich, durchs Bewubtsein von Menschen hindurch Präformiertes ist. (PhnM, 39). 
A nomeação adamítica está tão longe de ser jogo e arbítrio, que, ao contrário, justamente nela se confirma, como tal, a condição paradisíaca, que não precisava ainda lutar contra o significado comunicativo das palavras. Como as ideias se dão, de forma não intencional, no ato nomeador, assim têm de se renovar pela contemplação filosófica. Nessa renovação, restaura-se a percepção original das palavras. E por isso, no curso de sua história, tantas vezes objeto de zombaria, a filosofia tem estado, com razão, em luta pela representação de algumas poucas palavras, sempre das mesmas palavras - das ideias. ${ }^{32}$

A condição edênica dos nomes das coisas, nessa descrição de Benjamin, é análoga ao momento do Espírito [Geist] hegeliano antes de realizar-se, quando as contradições e seus movimentos de resolução ainda não haviam começado a se manifestar como história. O paralelo teológico desse momento seria tudo aquilo que é anterior à encarnação do logos como Filho. Franz Rosenzweig abordou esse tema em um capítulo, O pensamento contra a linguagem [Das Denken gegen die Sprache] de sua obra $A$ estrela da redenção [Der Stern der Erlösung]. Um nome próprio, para proteger sua dignidade, ${ }^{33}$ precisaria resguardar a mesma relação utópica e edênica de que gozava antes de ser incluído na sintaxe humana. Na condição de único (Adorno escreveria: não idêntico), o nome de cada coisa exigiria uma relação intersubjetiva ${ }^{34}$ - análoga à relação Eu-Tu de Martin Buber, em lugar de uma relação Eu-Isso. O nome de Deus seria o arquinome (próprio), o Nome que se oferece como nome primordial para todas as coisas. Segundo a relação

${ }^{32}$ Das adamitische Namengeben ist so weit entfernt Spiel und Willkür zu sein, daß vielmehr gerade in ihm der paradiesische Stand sich als solcher bestätigt, der mit der mitteilenden Bedeutung der Worte noch nicht zu ringen hatte. Wie die Ideen intentionslos im Benennen sich geben, so haben sie in philosophischer Kontemplation sich zu erneuern. In dieser Erneuerung stellt das ursprüngliche Vernehmen der Worte sich wieder her. Und so ist die Philosophie im Verlauf ihrer Geschichte, die so oft ein Gegenstand des Spottes gewesen ist, mit Grund ein Kampf um die Darstellung von einigen wenigen, immer wieder denselben Worten - von Ideen (BENJAMIN, Walter: Ursprung des deutschen Trauerspiels, p. 37).

${ }^{33}$ Kaufmann (p. 4) alude à moral kantiana quando examina a possibilidade de preservar-se o objeto da voracidade do conceito. Pela lei moral fundamental de Kant, é imperativo tomarse uma pessoa sempre como fim, nunca como meio. Transpondo essa máxima para o terreno da epistemologia, os objetos também não poderiam ser submetidos à classificação das propriedades que a eles aderem para uma finalidade que é alheia a eles, a de receberem um nome e, com isso, ingressarem no sistema sintático humano e serem apreendidos como conceito, e não como o objeto único que cada um é.

${ }^{34}$ Ver KAUFMANN, p. 4. 
que as coisas criadas têm com Deus, seus nomes não poderiam ser vilipendiados, isto é, se o Nome não pode ser inscrito em uma sintaxe e nem pronunciado, os nomes das coisas (todas com relação ontológica com o criador) também mereceriam a dignidade de ter um nome próprio infenso à inclusão em uma categoria.

O que tem um nome próprio não pode mais ser coisa, não pode mais ser de todos; ele é incapaz de ingressar na categoria sem deixar resto, pois não há nenhuma categoria a que pertença, ele é sua própria categoria. ${ }^{35}$

A culpa do pensamento por pensar, acredita Adorno, por querer apreender o heterogêneo, empurra-o para a dialética, na busca de uma solução. Entretanto, a própria atividade dialética é prova da consciência de que não há identidade. O pensamento teria consciência de sua não identidade, daí sua culpa por forçar o conceito como índice de igualdade entre objeto e pensamento. ${ }^{36}$

Para conciliar sujeito e objeto, Jüngel remete à categoria da fé: "A fé é ansiosa por pensar Deus". ${ }^{37}$ A fé, com sua ambição de pensar Deus, realizaria uma dialética negativa: ambas, fé e ratio manter-seiam intactas graças ao telos que comungam, que é pensar Deus. Esse pensar Deus, portanto, seria o ponto de encontro da ânsia tanto da fé quanto da racionalidade. E, na condição de logos encarnado, afirma Jüngel, Deus já demonstrou, com a morte na cruz, que o amor é a palavra definitiva de Deus para a humanidade: "A fé cristã parte do pressuposto de que Deus, com a palavra da cruz como evangelho, falou de forma definitiva a todos os homens". ${ }^{38}$ E a palavra da cruz, afirma Jüngel, seria condição preliminar para pensar-se Deus. ${ }^{39}$ Assim, o amor de Deus,

35 Was einen eigenen Namen hat, kann nicht mehr Ding, nicht mehr jedermanns Sache sein; er ist unfähig, restlos in die Gattung einzugehen, denn es gibt keine Gattung, der es zugehörte, es ist seine eigene Gattung (ROSENZWEIG, p. 208 ).

${ }^{36}$ Dialektik ist das konsequente Bewußtsein von Nichtidentität. Sie bezieht nicht vorweg einen Standpunkt. Zu ihr treibt den Gedanken seine unvermeidliche Insuffizienz, seine Schuld an dem, was er denkt. [Band 6: Negative Dialektik. Jargon der Eigentlichkeit: Einleitung. Digitale Bibliothek Band 97: Theodor W. Adorno: Gesammelte Schriften, S. 2834 (vgl. GS 6, S. 17)]

${ }^{37}$ Der Glaube ist darauf bedacht, Gott zu denken (JÜNGEL, p. 310).

${ }_{38}$ Der christliche Glaube geht dabei von dem Vorurteil aus, dass Gott im Wort vom Kreuz als dem Evangelium für alle Menschen definitiv zur Sprache gekommen ist (JÜNGEL, p. 308).

${ }^{39}$ Nur unter der Voraussetzung, dass Gott zur Sprache gekommen ist, ist der Versuch, Gott zu denken, überhaupt snnvoll (JÜNGEL, p. 313). 
consubstanciado na morte do logos encarnado na cruz, seria o falar de Deus à humanidade - um falar que prescinde de conceitos e que se comunica a todos os homens de forma igual. Então, se o falar de Deus é amor, o "pensar Deus" também é, necessariamente, amor. Esse pensar acontece concomitantemente à fé [Glaube], a qual pensa Deus por meio do amor. ${ }^{40}$ Como o Eros platônico, o amor cristão medeia e liga duas esferas irreconciliáveis na sintaxe iluminista, pensar e amar. ${ }^{41}$

De acordo com a negatividade da dialética adorniana, a recusa do objeto em "fazer sentido" equivale à resistência do Nome em ser pronunciado: "Em uma teologia seriamente 'dialética', mesmo o nome de Cristo deveria desaparecer. Caso contrário, será 'mediado". ${ }^{42}$ Forçar os objetos e seus nomes a servirem de protetores do sentido e da coerência é sintoma da dominação e destruição da natureza que o processo civilizatório faz crer ao homem que seja a única saída para evitar a barbárie. No final de contas, a barbárie da ratio é tão letal quanto a da regressão; o Esclarecimento cria novas mitologias. E, num mundo totalmente esclarecido, não há lugar para a finitude; para Adorno, o signo desse Esclarecimento total e totalizante é o cogumelo atômico: perfeito, tecnológico, avançadíssimo, mas que não admite o fator humano. ${ }^{43}$ Daí a importância, para Adorno, do refúgio do não idêntico representado pela obra de arte autônoma: ela, tanto quanto o Nome, se recusa à comunicação conceitual.

Todavia, como aquela totalidade se constrói de acordo com a lógica, cujo núcleo é formado pelo princípio do terceiro excluído, tudo o que não se encaixe nesse princípio, tudo o que seja qualitativamente

${ }^{40}$ Em Coríntios 1,1 a palavra da cruz é qualificada como "loucura": "Com efeito, a linguagem da cruz é loucura para os que se perdem, mas para aqueles que se salvam, para nós, é poder de Deus" $(1 C o r, 1)$. É loucura porque a ratio não adere a ela, já que não é conceitual. Em seguida $(1$ Cor, 19$)$, há uma alusão a Isaías: "Destruirei a sabedoria dos sábios e rejeitarei a inteligência dos inteligentes" $(I s, 29,14)$ : a palavra da cruz não pode, segundo o texto, ser apreendida racionalmente; como amor de Deus, ela é imediata e pré-racional.

${ }^{41}$ No Banquete, Platão apresenta o caminho ascendente do conhecimento erótico: quem busca o amor é atraído pela beleza e passa a amar os objetos belos. A partir dele, o filósofo vai amando, de objeto em objeto, e subindo até chegar ao conceito de amor.

${ }^{42}$ Selbst der Name Christi müßte in einer ernsthaft ,, dialektischen" Theologie untergehen. Oder: es wird dennoch ,, mediiert" [Band 2: Kierkegaard. Konstruktion des Ästhetischen: V. Zur Logik der „Sphären “. Digitale Bibliothek Band 97: Theodor W. Adorno: Gesammelte Schriften, S. 874 (vgl. GS 2, S. 141 ff.)].

${ }^{43}$ Aber die vollends aufgeklärte Erde strahlt im Zeichen triumphalen Unheils. [Band 3: Dialektik der Aufklärung: Begriff der Aufklärung. Digitale Bibliothek Band 97: Theodor W. Adorno: Gesammelte Schriften, S. 1105 (vgl. GS 3, S. 19)] 
diverso, recebe a marca da contradição. A contradição é o não idêntico sob o aspecto da identidade; o primado do princípio de não contradição na dialética mede o heterogêneo a partir do pensamento unitário. ${ }^{44}$

A recusa à comunicação conceitual como condição para a autonomia do ente é possível também na perspectiva de Jüngel, já que, para este, a teologia sempre procurou uma linguagem que correspondesse [que desse resposta] a Deus, na medida em que permitisse a Ele próprio se expressar, ${ }^{45}$ isto é, ser sujeito desse falar. Como Deus só pode ser concebido como sujeito incondicional de $\mathrm{Si}$ mesmo, faz parte desse incondicional ser-sujeito o revelar-Se como Deus. ${ }^{46}$

\section{Conclusão}

A apreensão do significado das proibições contidas no Segundo e Terceiro Mandamentos tem, como obstáculo, a suspeita de que a ratio, se for empregada nesse trabalho, possa destruir o objeto de estudo. A discussão sobre uma saída para essa aporia é um tema clássico da teologia, mas também da filosofia da religião. Neste artigo, que contrastou dois autores diferentes, Theodor Adorno e Eberhard Jüngel, foi possível observar alguns pontos onde o pensamento de ambos converge:

a) a crença de que o problema da potencialidade destrutiva da ratio - e de sua duvidosa capacidade comunicativa - não é apenas teórico, ao contrário, que de sua solução depende o resgate da ética em uma sociedade que se constituiu a partir de uma deformação do humano;

b) a determinação a enfrentar esse problema em seu fundamento, que é a linguagem, em vez de arriscar-se em um ativismo prático que, acreditam ambos, desvirtuaria a empreitada

\footnotetext{
${ }^{44} \mathrm{Da}$ aber jene Totalität sich gemäß der Logik aufbaut, deren Kern der Satz vom ausgeschlossenen Dritten bildet, so nimmt alles, was ihm nicht sich einfügt, alles qualitativ Verschiedene, die Signatur des Widerspruchs an. Der Widerspruch ist das Nichtidentische unter dem Aspekt der Identität; der Primat des Widerspruchsprinzips in der Dialektik mißt das Heterogene am Einheitsdenken. [Band 6: Negative Dialektik. Jargon der Eigentlichkeit: Einleitung. Digitale Bibliothek Band 97: Theodor W. Adorno: Gesammelte Schriften, S. 2834 (vgl. GS 6, S. 17)]

${ }^{45}$ Als solche ist sie (die Theologie) immer schon und immer wieder auf eine Sprache bedacht, die Gott entspricht, indem sie ihn selbst zur Sprache komen lässt (JÜNGEL, p. 308).

46 [...] Gott nur als unbedigntes Subjekt seiner selbst denkbar ist und dass es zu diesem unbedingten Subjektsein gehört, sich selbst als Gott zu offenbaren [...] (JÜNGEL, p. 309).
} 
e a poria em risco de ser cooptada por forças políticas regressivas;

c) a convicção de que os sistemas de pensamento totalizantes cumpriram sua promessa de libertar a humanidade do atraso científico, mas criaram outras dependências e limitações tão ou mais perigosas;

d) o reconhecimento de que, em que pese não se constituir em uma sucessão necessária de eventos como acreditava o Idealismo, a história é uma disciplina complementar imprescindível à filosofia e à teologia, e que de sua leitura em uma perspectiva humana e finita depende o entendimento e a solução do problema da relação sujeito/objeto ou Deus/ Nome.

Este artigo não pretendeu esgotar o tema, deve ser considerado um fragmento; ressalte-se que o autor acredita que seja possível o conhecimento no fragmentário e na incompletude. Um enriquecimento recomendável estaria em uma continuação que abordasse:

a) o falar de Deus com a ajuda da analogia;

b) uma revisão da história da teologia negativa, desde Dioniso Areopagita, a partir de uma perspectiva da filosofia da religião;

c) a questão dos fundamentos cognitivos da religião - recorde-se, a respeito, que desde o Contra Celso, de Orígenes, a racionalidade reivindica um lugar central na teologia. Seria de proveito uma comparação com o livro de Todd Tremlin (Minds and Gods - The Cognitive Foundations of Religion. New York, Oxford University Press, 2006) e seu sugestivo estudo sobre as raízes pré-históricas da mente moderna e da relação entre cognição e sistemas religiosos.

A procura por uma alternativa à ratio como linguagem e conceito não tem expectativa de fornecer uma solução definitiva ao problema da dizibilidade de Deus (Jüngel) e das coisas (Adorno), já que isso confirmaria a vitória de uma concepção totalizante do conhecimento. Um trabalho de arqueologia, como entendido por Foucault (A arqueologia do saber), onde a escavação é o que se pode conhecer, teria mais afinidade com as propostas de Jüngel - de Deus como devir - e de Adorno de procurar à frente, na história, uma constelação utópica e edênica que conciliasse nomes e entes, ao mesmo tempo em que preservasse a sagrada individualidade das coisas. 


\section{Referências}

ADORNO, Theodor W. Kierkegaard. Konstruktion des Ästhetischen. Frankfurt: Suhrkamp, 1986.

. Kulturkritik und Gesellschaft I/II: Ohne Leitbild. Frankfurt: Suhrkamp, 1986. . Minima moralia - Reflexionen aus dem beschädigten Leben. Frankfurt: Suhrkamp, 1986. . Negative Dialektik. Frankfurt: Suhrkamp, 1986. . Philosophie der neuen Musik. Frankfurt: Suhrkamp, 1986. . Reaktion und Fortschritt. In: ADORNO, Theodor W. und KRENEK, Ernst: Briefwechsel. Hsg. Wofgang Pogge. Frankfurt: Suhrkamp, 1974.

. Über das gegenwärtige Verhältnis von Philosophie und Musik. Frankfurt: Suhrkamp, 1986.

ADORNO, Theodor W.; HORKHEIMER, Max. Dialektik der Aufklärung. Frankfurt: Suhrkamp, 1986.

BENJAMIN, Walter. Ursprung des deutschen Trauerspiels. Frankfurt: Suhrkamp, 1987.

CHOURAQUI, André. Iohanân (O Evangelho segundo João). Rio de Janeiro: Imago, 1997.

FILLION, Christine. Adorno's Marginalien zu Theorie und Praxis. In: HUMANITAS Victoria University Undergraduate Journal for Humanities. $<$ https://humanitasjournal. files.wordpress.com/2012/12/volume-2-issue-2_fall-2012-final.pdf>.

HEGEL, Georg W. Phenomenologie des Geistes. Stuttgart: Philip Reclam, 1996.

JÜNGEL, Eberhard. Gott als Geheimnis der Welt - Zur Begründung der Theologie des Gekreuzigten im Streit zwischen Theismus und Atheismus. Tübingen: J.C.B. Mohr, 1977.

. Gottes Sein ist im Werden. Verantwortliche Rede vom Sein Gottes bei Karl Barth, eine Paraphrase. Tübingen: Mohr Verlag, 1967.

KAUFMANN, David. Adorno and the Name of God. <http://webdelsol.com/ FLASHPOINT/adorno.htm>.

ULLMANN, Reinholdo Aloysio. Plotino - um estudo das Enéadas. Porto Alegre: EDIPUCRS, 2008.

RILKE, Rainer Maria. Das Stunden-Buch. Leipzig: Insel Verlag, 1912.

ROSENZWEIG, Franz. Der Stern der Erlösung. Frankfurt: Suhrkamp, 1988.

SCHÜLER, Donaldo. Heráclito e seu (dis)curso. Porto Alegre: L\&PM, 2000. 